\title{
USING KHAT (Catha edulis) LEFTOVER MEAL AS FEED FOR SHEEP: ITS IMPLICATION ON FEED INTAKE, DIGESTIBILITY AND GROWTH
}

\author{
Abadi BRHANU1 ${ }^{1}$ and Tikabo GEBREMARIAM $2 \times \bowtie$ \\ 1Maichew Agricultural Technical Vocational Education and Training (ATVET) College, Maichew, Tigray, Ethiopia \\ 2Department of Animal, Rangelands and Wildlife Sciences, Mekelle University, Mekelle, Ethiopia \\ Email: tikabomariam@gmail.com; ORCID: 0000-0002-2672-861X \\ Supporting Information
}

\begin{abstract}
Ninety days feeding trial was conducted with the aim to evaluate the impact of replacing concentrate mix with dried khat (Catha edulis) leftover meal on feed intake, body weight change and digestibility of Tigray Highland sheep fed a basal diet of mixed grass hay. The trial was carried out using 24 lambs $(17.8 \pm 1.08 \mathrm{~kg})$ with six blocks and four treatments in a randomized complete block design (RCBD). Concentrates mix was substituted with khat leftover meal at a ratio of $0 \%$ (T1), $15 \%$ (T2), 30\% (T3) and $45 \%$ (T4) on DM basis. The dietary rations were formulated in iso-nitrogenous to meet the nutrient requirements of lambs. Data was analyzed by analyses of variance (ANOVA) using the General Linear Model (GLM) procedures of SAS (2008). Treatment means comparison was done using Tukey's HSD test at $P<0.05$. Dried khat leftover meal had moderate crude protein (12.3\%) and less NDF value (31.9\%). Substituted concentrates mix with $15 \%$ khat leftover meal had better impact $(P<0.001)$ on lamb's total $D M, O M, M E, A D L$ and ADF intake compared to the lambs dietary T3 and T4. Daily weight gain and feed conversion efficiency were significant $(P<0.001)$ till substituted concentrates mix with $30 \%$ khat leftover meal. Diet digestibility showed reducing as inclusion level of khat meal increased across treatment. It is concluded that khat leftover meal can be utilized up to $30 \%$ without deleterious effect on animal performance and health.
\end{abstract}

Keywords: Body Weight, Digestibility, Feed Intake, Khat Leftover.

Abbreviations: ADF: Acid detergent fiber; ADL: Acid detergent lignin; ANOVA: Analyses of variance; AOAC: Association of Official Analytical Chemists; ATVET: Agricultural Technical Vocational Education and Training; CP: Crude protein; CSA: Central Statistical Agency; DC: Digestibility Coefficient; DM: Dry matter; FCE: Feed conversion efficiency; GLM: General Linear Model; HSD: Honest Significant Difference; m.a.s.l: Meter above sea level; ME: Metabolizable energy; MR: Mixed ration; MSE: Mean standard error; NDF: Neutral detergent fiber; NFE: Nitrogen free extract; NRC: National Research Council; OM: Organic matter; RCBD: Randomized complete block design; SAS: Statistical Analysis System; SL: Level of significance; TDMI: Total dry matter intake.

\section{INTRODUCTION}

The plant Khat (Catha edulis) is an evergreen perennial shrub plant that belongs to the Celastraceae family and is believed to be originated in Ethiopia (Lemessa, 2001). The plant is widely grown in different parts of Ethiopian including southern zone of Tigray. The total area of land under khat cultivation is estimated at 249, 358.02 hectare in Ethiopia where it has got the status of cash crop (CSA, 2015). A survey done in Raya-Azebo district reported that a household, on average, holds about 0.47 hectare lands covered by khat plantation as source of cash crop (Desalegn, 2017). Khat leftovers include the unused parts of the khat crop: hard leaves, branches and twigs that disposed by the producers, traders and consumers. The leftovers are largely utilized as non-conventional feed resources for livestock especially goats and sheep.

Many research evidences showed the importance of khat as animal feed source (Mekasha et al., 2008; Getinet and Yoseph, 2014; Woldu et al., 2015). The khat leftover leaves have high levels of ash, and nitrogen free extract (NFE) with fiber content expressed as neutral detergent fiber and acid detergent fiber and moderate crude protein (CP) content (Getinet and Yoseph, 2014). Furthermore, khat leftovers contain higher $\mathrm{Ca}$ and $\mathrm{Mg}$ but lower $\mathrm{K}$ and Mn levels than did other feeds (Mekasha et al., 2008). This implies the potential use of khat leftover as alternative feed source for livestock in replacing the expensive commercial feeds and thereby reducing production costs. Despite of its wide availability, however, little research efforts are so far done to see its impact on ruminant feed intake, digestibility and growth performance especially in its meal form. The objective of this study was to evaluate the impact of replacing concentrate mix with dried khat leave meal on feed intake, body weight change and digestibility of Tigray Highland sheep fed a basal diet of mixed grass hay. 


\section{Descriptions of the study area}

The experiment was conducted at Maichew Agricultural Technical Vocational Education and Training (ATVET) College, located at $12^{\circ} 47^{\prime} \mathrm{N}$ latitude and $39^{\circ} 32^{\prime}$ East longitude with altitude of $2432 \mathrm{~m}$.a.s.l in southern zone of Tigray, northern Ethiopia. The mean annual rainfall ranges 600 to $800 \mathrm{~mm}$ and the average annual minimum and maximum temperature is $12^{\circ} \mathrm{C}$ and $24^{\circ} \mathrm{C}$, respectively. Mixed crop-livestock farming system is the main feature of the study area (Moges, 2015).

\section{Experimental animal managements}

Twenty-four uncastrated Tigray Highland lambs $(17.8 \pm 1.08 \mathrm{~kg})$ were bought from local market. The experimental lambs were quarantined for two weeks to adapt them to the new environment and to observe their health condition before conducting the experiment. During this period, the lambs were drenched with broad spectrum Anthelmintic of $300 \mathrm{mg}$ per lambs against internal parasites, sprayed with $12.5 \%$ diazinone against external parasites and were vaccinated against common infectious disease, with $1 \mathrm{ml}$ anthrax vaccine and $1 \mathrm{ml}$ PPR per lambs. The experimental animals were adapted to the feeds, feeding schedule and pen environment for about 14 days.

\section{Feeds and feeding managements}

The experimental feeds consisted of mixed grass hay, air dried khat leftover meal and concentrate mixture. The mixed grass hay was chopped, weighed and offered to the lamb's ad libitum allowing $20 \%$ refusal. Concentrate ingredients (noug seed cake, wheat short, maize grain and sesame seed cake) and salt were purchased from local market. Khat leftovers were collected from khat traders and producers and were air dried for five to six days under shade by spreading on plastic sheets. Further, to make easy for formulation, air dried khat leftovers were crushed and woody parts were removed at Bokra union feed processing. The supplement feeds were offered in two equal portions twice a day (08:00 and 16:00 hours) after the animals well fed hay and clean water. The management practices of all the animals irrespective of groups were similar. The feed supply to the sheep was adjusted every ten days on the basis of their body weight changes.

\section{Experimental design and treatments}

The feeding trial was undertaken using RCBD with four treatments and six replications. The lambs were allocated to blocks based on their initial basis of live body weight which was determined by two consecutive weighing after overnight fasting. Each treatment was randomly allocated to the lambs of a given block independently for each block. Dietary feed treatments were arranged in such a way that concentrates mix substituted with khat leftover meal at a ratio of $0 \%$ (T1), $15 \%$ (T2), 30\% (T3), and 45\% (T4) on DM basis (Table 1). The experimental treatment diets were offered as gram/sheep/day on DM basis. The dietary rations were formulated to be iso-nitrogenous to meet the nutrient requirements of lambs based on the recommendation of NRC (1984). The trial lasted 90 days with additional 14 days of adaptation periods.

\section{Table 1 - Proportion of ingredients (\%) used in formulating the experimental rations}

\begin{tabular}{lcccc}
\hline \multirow{2}{*}{ Feed ingredients } & \multicolumn{3}{c}{ Treatments } \\
\cline { 2 - 5 } & T1 & T2 & T3 & T4 \\
\hline Mixed grass hay & Ad libitum & Ad libitum & Ad libitum & Ad libitum \\
Wheat short & 30 & 13 & 10 & 5 \\
Maize grain & 17 & 20 & 10 & 2 \\
Noug seed cake & 28 & 11 & 17 & 13 \\
Sesame seed cake & 22 & 38 & 30 & 32 \\
Mineral salt & 3 & 3 & 3 \\
Total & 100 & 100 & 100 \\
T1= 100\% concentrate mix +mixed grass hay; T2 = mixed grass hay + 85 \% concentrate mix + 15 \% khat leftover meal; T3=mixed grass hay \\
70\% concentrate mix + 30\% kh at leftover meal; T4 = mixed grass hay + 55\% concentrate mix + 45\% khat leftover meal
\end{tabular}

Data measurements and observations ,Feed intake and feed conversion efficiency

The amount of feed offered and refused for each sheep was measured every day for the whole experimental period. The feed intake was calculated by subtracting the refusal from the offered feed. Nutrient intake was calculated as the difference between nutrients offered and refused. Feed conversion efficiency was calculated as the body weight gain divided by feed intake. Representative feed samples (hay, khat leftover and concentrates mix) were taken and kept for chemical analysis. 
weight gain was calculated as the difference between final and initial body weight. Average daily gain (g/day) was calculated as the difference between final and initial body weights divided by feeding time.

\section{Diet apparent digestibility measurement}

The digestibility trial was conducted following the feeding trial using the same animals, dietary treatments and feeding schedule. The animals were adapted to the carrying fecal bags for three days followed by fecal collection for seven consecutive days. Feces voided was collected daily per animal and weighed every morning before feed offer. Out of the daily fecal excretion, $20 \%$ was sampled and pooled to make a composite sample for each animal over the collection period. The fecal samples were stored at -200 in between collections. Fecal samples were dried in an oven at $65 \mathrm{C}$ for 48 hours and ground to pass $1 \mathrm{~mm}$ screen sieve. The ground samples were stored in an airtight plastic bags pending chemical analysis. Feed intake was recorded daily. A weekly composite sample of each feed and refusal for each animal was taken during digestibility trial. Refusal samples were then pooled per treatment. Body weights at the beginning and end of the digestibility trial was taken for each animal. Apparent digestibility coefficient (DC) of each nutrient (OM, CP, NDF, ADF and ADL) was calculated using the general formula as below (McDonald et al., 2002).

Digestibility coefficient $(\mathrm{DC})(\%)=\underline{\mathrm{DM}} /$ nutrient consumed $-\mathrm{DM} /$ nutrients excreted in feces $\mathrm{x} 100 / \mathrm{DM} /$ nutrients consumed

\section{Chemical analysis of samples}

Representative samples of feed offered, refusals and feces were ground to pass a $1 \mathrm{~mm}$ sieve mesh after drying the samples at $65 \mathrm{C}$ for 48 hours. The DM, ash and nitrogen contents of feces were analyzed using the procedure of AOAC (2005) and crude protein (CP) was calculated as $N * 6.25$. Organic matter (OM) was calculated as the difference between 100 and ash content. Neutral detergent fiber (NDF), acid detergent fiber (ADF) and acid detergent lignin (ADL) were determined through the procedures of Van Soest et al. (1994).

\section{Statistical analysis}

Data was analyzed by analyses of variance (ANOVA) using the General Linear Model (GLM) procedures of SAS (2008). Treatment means comparison was done using Tukey's HSD (Honest Significant Difference) test at $P<0.001$.

\section{RESULTS}

\section{Chemical composition of ingredients and experimental rations}

The chemical composition of feed ingredients and experimental rations is presented in Table 2 . The nutrient content of experimental feeds varied as they came from different sources. The CP content of mixed grass hay (8.99\%) was sufficient to meet the maintenance requirement, but it was relatively low to meet the growth demands of experimental animals. Khat leftover meal had medium CP content (12.3\%) when measured in view of rumen microbial requirement but it was lower when compared to the commercial feeds: noug seed cake (33.1\%), sesame seed cake (31.8\%) and wheat short (18.8\%). The result also showed that khat leftover meal had lowest NDF content (31.9\%) as compared to hay $(66.8 \%)$, noug seed cake $(62.7 \%)$, sesame cake $(62.8 \%)$ and wheat short $(42.3 \%)$ but higher than that maize grain (29.1\%). The metabolizable energy content of khat leftover meal (7.18 MJ/kg DM) was higher compared to that of sesame seed cake $(6.21 \mathrm{MJ} / \mathrm{kg} \mathrm{DM})$ but far lower than that of maize grain (13.52 MJ/kg DM) and wheat short (12.32 $\mathrm{MJ} / \mathrm{kg} \mathrm{DM})$. The ash content of khat leftover was $7.36 \%$ which is lower than noug seed cake (11.4\%) but higher than wheat short (4.16\%).

The CP of the experimental rations was almost similar (21 to $24 \%$ ) and this was due to the fact that the dietary treatments were made deliberately to have similar protein contents. The NDF content of dietary T1 (0\% khat meal) was higher than dietary T2 (15\% khat meal), T3 (30\% khat meal) and T4 (45\% khat meal) in that order showing decrements trend with increase of khat leftover meal along treatments. On the contrary, the ADF and ADL values showed increment with increasing inclusion level of khat meal. The ash amount (7.36\% for T1 and $9.26 \%$ for T4) showed increment with level of khat meal. The energy concentration was decreased with khat meal level with the highest in T1 (9.45 ME MJ/kg $\mathrm{DM})$ and the lowest in T4 (6.55 ME MJ/kg DM).

\section{Dry matter and nutrient intake}

The mean daily DM and nutrient intake of Tigray Highland sheep across the dietary treatments are presented in Table 3. The mixed grass hay DM intake expressed as gram per day was significantly different among the treatments $(\mathrm{P}<0.001)$. Sheep with dietary T1 (0\% khat meal) and T2 $(15 \%$ khat meal) had the highest $(\mathrm{P}<0.001)$ basal mixed grass hay DM intake than those sheep with T3 (30\%) and T4 (45\%). However, no significant differences were observed among the sheep in T1 and T2 ( $>$ >0.05). The highest total DM, OM and ME intake was recorded for sheep placed under T1 and T2 followed by sheep in T3 and T4 in descending order. But no significant difference was observed in sheep groups fed on T1 and $T 2$ in this regard $(P>0.05)$. The $C P$ and NDF intake showed decreasing across treatments $(P<0.001)$ with increasing inclusion level of khat. 


\section{Body weight change}

There was no initial body weight differences $(P>0.05)$ among the experimental sheep. The dietary treatments had no significant effects $(P>0.05)$ on the final live weight and body weight change of the experimental sheep among the T1 (0\% Khat leftover meal), T2 (15\% Khat leftover meal) and T3 (30\% Khat leftover meal) but significantly $(P<0.001)$ lower final weight was recorded in animals fed on T4 (45\% Khat leftover meal). Similarly, daily body weight gain did not show significant difference $(P>0.05)$ up to $30 \%$ khat meal inclusion level but it was lower in $45 \%$ (T1) (P<0.001). Feed conversion efficiency was not significantly different amongst T1, T2 and T3 (P>0.05) but it was lower for T4 (P<0.05).

\section{Apparent nutrient digestibility}

Dry matter and nutrient digestibility coefficients of the experimental diets are presented in Table 5. There was significant difference among the treatments in DM and nutrient digestibility $(P<0.05)$. Sheep with dietary T1 and T2 had higher $(P<0.001)$ DM, OM and CP digestibility coefficients than dietary T3 and T4. Likewise, sheep fed on dietary T1 and T2 had higher NDF and ADF apparent digestibility coefficient than T3 and T4. However, there was no significant difference among dietary T1 and T2 in DM, OM, CP, NDF and ADF apparent digestibility coefficient $(P>0.05)$.

\section{Table 1 - Chemical composition of feed ingredients and experimental diets}

\begin{tabular}{|c|c|c|c|c|c|c|c|c|}
\hline $\begin{array}{ll}\text { Feed ingredients } & \text { Feed type } \\
\end{array}$ & DM\% & OM & Ash & CP & NDF & ADF & $\overline{A D L}$ & $\mathrm{ME}(\mathrm{MJ} / \mathrm{kg})$ \\
\hline Mixed grass hay & 94.67 & 90.67 & 9.33 & 8.99 & 66.8 & 40.5 & 5.38 & 8.16 \\
\hline Sesame cake & 96.82 & 90.09 & 9.91 & 31.8 & 62.8 & 29.6 & 8.25 & 6.21 \\
\hline Maize grain & 94.86 & 96.49 & 3.51 & 7.09 & 29.1 & 4.71 & 2.70 & 13.52 \\
\hline Noug seed cake & 95.84 & 88.26 & 11.4 & 33.1 & 62.7 & 29.5 & 9.23 & 7.03 \\
\hline Wheat short & 94.35 & 95.84 & 4.16 & 18.8 & 42.3 & 6.57 & 1.19 & 12.32 \\
\hline Khat leftover meal & 88.91 & 92.64 & 7.36 & 12.3 & 31.9 & 26.1 & 10.19 & 7.18 \\
\hline \multicolumn{9}{|l|}{ Treatment rations } \\
\hline MR-T1 & 94.00 & 92.53 & 7.47 & 24.5 & 54.6 & 18.5 & 5.31 & 9.45 \\
\hline MR-T2 & 94.00 & 91.72 & 8.28 & 21.2 & 52.0 & 23.7 & 7.36 & 8.48 \\
\hline MR-T3 & 94.00 & 90.76 & 9.24 & 20.8 & 46.5 & 27.7 & 9.59 & 7.01 \\
\hline MR-T4 & 94.00 & 90.74 & 9.26 & 21.6 & 48.8 & 28.4 & 10.10 & 6.55 \\
\hline
\end{tabular}

Table 2 :Dry matter and nutrient intake of Tigray Highland sheep consumed mixed grass hay and supplemented with concentrate, khat leftover meal or their mixtures

\begin{tabular}{|c|c|c|c|c|c|c|}
\hline \multirow{2}{*}{ Intake (g/day) } & \multicolumn{6}{|c|}{ Treatments } \\
\hline & T1 & T2 & T3 & T4 & MSE & $\mathrm{SL}$ \\
\hline Hay DM & $495.99^{a}$ & $479.27^{\mathrm{ba}}$ & $467.50^{b}$ & $365.81^{c}$ & 12 & $\star *$ \\
\hline Supplement DM & $303.70^{a}$ & $303.70^{a}$ & $303.70^{a}$ & $303.70^{a}$ & 0 & ns \\
\hline Total DM & 799.77a & 783.04 & $771.28^{b}$ & $650.09 c$ & 12 & ** \\
\hline Ash & $68.97^{b}$ & 69.87ba & $71.68^{a}$ & $60.44^{b}$ & 1 & $\star *$ \\
\hline OM & $730.77^{a}$ & 713.15ba & $699.57^{b}$ & $589.63^{c}$ & 11 & $\star *$ \\
\hline CP & $117.97^{a}$ & $108.77^{b}$ & $103.96^{c}$ & $95.7^{d}$ & 1 & $\star *$ \\
\hline NDF & $497.18^{a}$ & $478.12^{b}$ & $453.55^{c}$ & $379.58^{d}$ & 8 & $* *$ \\
\hline ADF & $257.08^{b}$ & $266.1^{a}$ & $273.48^{a}$ & $226.53^{c}$ & 5 & $* *$ \\
\hline ADL & $42.8^{d}$ & $48.14^{c}$ & $54.28^{a}$ & $49.31^{b}$ & 0.6 & $* *$ \\
\hline $\mathrm{ME}(\mathrm{MJ} / \mathrm{Kg})$ & $69.18^{a}$ & $64.88^{\text {ba }}$ & $59.45^{c}$ & $48.17^{d}$ & 1 & $\star *$ \\
\hline
\end{tabular}

Table 3 - Body weight change and feed conversion efficiency of Tigary Highland sheep consumed mixed grass hay and supplemented with concentrate mixture, Khat leftover meal or their mixture

\begin{tabular}{|c|c|c|c|c|c|c|}
\hline Treatments & T1 & T2 & T3 & T4 & MSE & SL \\
\hline Initial body weight (kg) & $17.66^{a}$ & $17.92^{\mathrm{a}}$ & $17.83^{a}$ & $17.83^{a}$ & 0.33 & ns \\
\hline Final body weight (kg) & $22.25^{a}$ & $22.33^{a}$ & $22.16^{a}$ & $20.9^{b}$ & 0.51 & ** \\
\hline Total body weight change (kg) & $4.60^{a}$ & $4.42^{a}$ & $4.33^{a}$ & $3.083^{b}$ & 0.67 & ** \\
\hline Average daily gain (g/day/head) & $56.6^{a}$ & $54.5^{a}$ & $53.5^{a}$ & $38.06^{b}$ & 4.5 & ** \\
\hline FCE (ADG/TDMI) & $0.07^{a}$ & $0.069^{a}$ & $0.069 a$ & $0.058^{b}$ & 0.06 & * \\
\hline
\end{tabular}


Table 4 - Dry matter and nutrient apparent digestibility coefficient (\%) of Tigray Highland sheep fed rations containing different levels of Khat leftover meal.

\begin{tabular}{|c|c|c|c|c|c|c|}
\hline $\begin{array}{l}\text { Treatments } \\
\text { Digestibility }\end{array}$ & T1 & T2 & T3 & T4 & MSE & SL \\
\hline DM & $62.59^{a}$ & $59.04^{\text {ba }}$ & $55.74^{c}$ & $50.89^{c}$ & 2.5 & ** \\
\hline OM & $69.65^{a}$ & $69.57^{a}$ & $66.44^{b}$ & $64.34^{b}$ & 1.8 & ** \\
\hline $\mathrm{CP}$ & $87.22^{a}$ & $84.98^{b}$ & $83.28^{c}$ & $81.95^{c}$ & 0.92 & ** \\
\hline NDF & $63.72^{b}$ & $69.59^{a}$ & $50.62^{c}$ & $44.88^{d}$ & 2.5 & ** \\
\hline ADF & $39.15^{b}$ & $47.67^{a}$ & $39.15^{b}$ & $27.44^{c}$ & 3.5 & ** \\
\hline
\end{tabular}

\section{DISCUSSIONS}

The dry matter (DM), organic matter (OM), neutral detergent fiber (NDF), acid detergent fiber (ADF) and ash content of mixed grass hay used in the present experiment was almost similar with other authors (Alemu et al., 2014; Gebru and Tesfay, 2017). The DM, CP and ash contents of the commercial feeds: noug seed cake, sesame cake and wheat short were comparable with previous studies (Gebru and Tesfay, 2017; Mekasha et al., 2008).

The DM, OM and ADF contents of khat leftover meal seen in this study was comparable with other research work (Getinet and Yoseph, 2014). However; the CP content was higher than the value reported by the same authors (Getinet and Yoseph, 2014). Khat leftover meal has moderate crude protein content $(12.3 \%)$ indicating its potential use as protein supplementation for the roughage-based ruminant animals. The medium CP value of khat meal is believed to be sufficient for rumen function (McDonald et al., 2002). The lower fiber value of khat meal as compared to the basal feed (hay) and commercial concentrate can enhance diet digestibility (McDonald et al., 2002). The NDF, ADL and ash content were less than the value reported by Getinet and Yoseph (2014) for khat meal and Gebru and Tesfay (2017) for Acacia saligna pod meal. This variation could be raised from maturity and species of the khat plant, soil fertility where the khat plant grown and the season of the leaf harvest. The energy value of khat meal (7.18 $\mathrm{ME} \mathrm{MJ} / \mathrm{kg} \mathrm{DM})$ was slightly higher than sesame cake (6.21 ME MJ/kg DM) but lower than maize grain (13.52 ME MJ/kg DM).

All the dietary treatments had almost similar CP value which was made intentionally to create iso-nitrogenous rations. The fiber content (NDF) showed reducing across treatments (T1 to T4) with increasing inclusion level of khat meal. This is attributed to the lower fiber content of khat meal when compared to commercial feeds. Similarly, the increased ash amount across treatment is attributed to the higher ash content of khat meal. On the other hand, the reducing trend of energy value (9.45 to $6.55 \mathrm{ME} \mathrm{MJ/kg} \mathrm{DM)} \mathrm{along} \mathrm{treatments} \mathrm{is} \mathrm{apparently} \mathrm{related} \mathrm{to} \mathrm{the} \mathrm{lower} \mathrm{energy} \mathrm{content} \mathrm{of} \mathrm{khat}$ meal as compared to commercial feeds.

Basal mixed hay DM intake in this study was higher than the value reported by Getinet and Yoseph (2014). All experimental sheep consumed the dietary supplement without any refusal across the experiment. The higher feed and nutrient intake in sheep groups in T1 (0\% khat meal) and T2 (15\% khat meal) could be attributed to the lower ADF and higher energy contents. Similarly, by increasing the total amount of concentrate offered, cows had higher DM and energy intake, which resulted in increased milk production and reduced negative energy balance and body condition score loss (Lawrence et al., 2015). Jung and Allen (1995) also insisted that cell-wall concentration and digestibility limit the intake potential and energy availability of forage crops in ruminant production. The indifference in DM intake between T1 and T2 might be explained by their similar apparent digestibility. The study showed decrease in dry matter intake with increasing level of khat leftover meal across the treatments. This could be explained by the higher ADF and ADL content of khat meal. Likewise, decreased DM intake was reported by Getinet and Yoseph (2014) in goats fed on $100 \%$ khat leftover meal. Conversely, increased feed intake and digestibility was seen in Somali goats when sorghum stover was replaced by khat leftover meal up to $60 \%$ on DM base (Tamir and Ismail, 2006).

Sheep placed in dietary T1, T2 and T3 had heavier total body weight change and average daily weight gain than sheep in dietary T4 and the difference might be most likely due to the reflection dense nutrient content (energy concentration) and higher feed intake. Mahgoub et al. (2000) reported that sheep fed high energy diet had heavier body weight than sheep fed medium and low energy diets. In support of this finding, Wallie et al. (2012) obtained that mixtures of different proportions of dried khat leftover meal and concentrate supplementation resulted in differences in daily body weight gain in goat. The same authors added that feeding leftover khat to goats consuming low to moderate quality forage-based diets can increase growth performance. Supplementation of dried khat leftover meal up to $45 \%$ of the diet DM has no deleterious effects on the performance and health of sheep. The daily body weight gain ( 53 to $56 \mathrm{~g} /$ day) was comparable to $63.89 \mathrm{~g} /$ day gain of Tigray Highland ram fed on mixed grass hay ad libitum and supplemented with $200 \mathrm{~g}$ of air dried Acacia saligna leaves and $200 \mathrm{~g}$ wheat bran (Gebru and Tesfay, 2017) and value reported by Getinet and Yoseph (2014).

The apparent digestibility coefficient of dry matter and nutrients showed decrements trend with increase of khat leftover meal level across dietary treatments. Nutrient apparent digestibility decline was observed when moving from dietary T1 and T2 to dietary T3 and T4 fed groups. This might be related to the higher cell wall fraction contents of dietary T3 and T4 as well as negative association effect of lower nutrient intake. McDonald et al. (2002) noted that the fiber fraction of a food has the greatest influence on its digestibility. However, there was no significant difference among 
dietary $\mathrm{T} 1$ and $\mathrm{T} 2$ in DM, OM and CP apparent digestibility coefficient and this was mainly due to positive association effect and similarity in their total DM and nutrient intake. It has long been recognized that in ruminants there is a positive relationship between the digestibility of foods and their intake (McDonald et al.,, 2002).

\section{CONCLUSIONS}

The study showed that khat leftover meal has moderate crude protein content indicating its potential use as protein supplementation for the roughage-based ruminant animals. No significant change was observed in feed intake and growth performance with increasing levels of khat meal substitution till $30 \%$ to concentrate mixture. This implies that khat leftover meal can be utilized as alternative option in the animal feeding system. Hence, it can be concluded that khat leftover meal can be included up to $30 \%$ in the animal ration without negatively affecting performance and health of ruminant animals.

\section{DECLARATIONS}

\section{Corresponding author}

Email: Adonayabadi@Gmail.Com,Tikabomariam@Gmail.Com

Mobile: +251-914757236,+251-914757236; ORCID: 0000-0002-2672-861X

\section{Competing interest}

The authors declare that they have no competing interests.

\section{Acknowledgement}

The authors acknowledge Maichew ATVET College and Mekelle University for financial and logistic support to undertake this study. In addition, the authors express appreciation to the Africa RISING research project for financial assistance.

\section{REFERENCES}

Alemu B, Animut G and Tolera A (2014). Effect of Millettia ferruginea (Birbra) foliage supplementation on feed intake, digestibility, body weight change and carcass characterstics of Washera sheep fed natural pasture mixed grass hay basal diet. SpringerPlus, 3(1):50. DOI: 10.1186/2193-1801-3-50

AOAC (2005). Official Methods of Analysis. 18th Ed, Association of Official Analytical Chemists, Washington DC, Method 935.14 and 992.24.

CSA (Central Statistical Agency) (2015). Report on area and production of major crops. Volume I, Statistical bulletin 278 , Addis Ababa, Ethiopia

Desalegn G (2017). Comparative assessment of biomass and soil carbon stock in multistrata agroforestry system and chat: the case of Raya Azebo, Tigray, Ethiopia. An MSc. Thesis Presented to School of Graduate Studies of Hawasa University. Dire-Dawa, Ethiopia.

Gebru G and Tesfay Y (2017). Utilization of wheat bran and dried Acacia saligna (Labill) HL Wendl leaves by highland rams. African Journal of Agricultural Research, 12(15): 1286 - 1292. DOI: 10.5897/AJAR2015.10376

Getinet $Y$ and Yoseph M (2014). Effect of feeding concentrate, dried khat (catha edulis) leftover or their mixtures on feed intake, digestibility and body weight change of Hararge highland goats fed basal diet of natural grass hay. The Journal of Animal and Plant Sciences, 24(1): 35 - 42.

Jung $H$ and Allen $M$ (1995). Characteristics of plant cell walls affecting intake and digestibility of forages by ruminants. Journal of Animal Science, 73(9): 2774 - 2790. DOI: 10.2527/1995. 7392774x

Lawrence D, O'donovan M, Boland T, Lewis E and Kennedy E (2015). The effect of concentrate feeding amount and feeding strategy on milk production, dry matter intake and energy partitioning of autumn-calving Holstein-Friesian cows. Journal of Dairy Science, 98(1): 338 - 348. DOI: 10.3168/jds.2014-7905

Lemessa D (2001). Khat (Catha edulis): botany, distribution, cultivation, usage and economics in Ethiopia. Addis Ababa: UNEmergencies Unit for Ethiopia.

Mahgoub 0, Lu C and Early R (2000). Effects of dietary energy density on feed intake, body weight gain and carcass chemical composition of Omani growing sheep. Small Ruminant Research, 37: 35 - 42. DOI: 10.1016/S0921-4488(99)00132-7

McDonald P, Edwards RA, Greenhalgh JFD and Morgan CA (2002). Animal Nutrition, 6th ed., Prentice Hall, London. Pp 464 479.

Mekasha Y, Tegegne A and Rodriguez-Martinez H (2008). Feed Intake and Sperm Morphology in Ogaden Bucks Supplemented with Either Agro-industrial By-products or Khat (Catha edulis) Leftover. Reproduction in Domestic Animals, 43(4): 437 - 444. DOI: 10.1111/j.1439-0531.2007.00931.x

Moges A (2015). Effects of different nitrogen rate and plant population density on yield and yield related traits. A MSc. Thesis Presented to School of Graduate Studies of Haramaya University. Dire-Dawa, Ethiopia.

NRC (National Research Council) (1984). Nutrient Requirements for Sheep: 6th Revised Edition, National Academy Press, Washington DC, USA.

SAS (Statistical Analysis System) (2008). SAS/STAT. 9.2 user's guide. Cary, NC. SAS Institute Inc. United States of America. 
Tamir B and Ismail M (2006). Effect of supplementing different levels of leftover of khat (Catha edulis) to sorghum stover on nutrient intake and digestibility by goats. Tropical Science, 46(4): 213 - 215. DOI: 10.1002/ts.180

Van Soest PJ (1994). Nutritional ecology of the ruminant, Cornell University Press.

Wallie M, Mekasha Y, Urge M, Abebe G and Goetsch A (2012). Effects of form of leftover khat (Catha edulis) on feed intake, digestion and growth performance of Hararge Highland goats. Small Ruminant Research, 102(1): 1 - 6. DOI: 10.1016/j.smallrumres.2011.07.014

Woldu Z, Belew D and Benti T (2015). The coffee-khat interface in Eastern Ethiopia: a controversial land use and livelihood change scenario. Journal of Agriculture Science and Technology, 5(3): 149 - 169. D0I: 10.17265/21616264/2015.03B.001 